\title{
(In)acessibilidade arquitetônica e suas implicações para a permanência da pessoa com deficiência visual no ensino superior
}

(In) architectural accessibility and its implications for the permanence of the person with visual impairment in higher education

\author{
J. D. A. Araújo ${ }^{1}$, M. A. B. Silva ${ }^{2}$ W. D. A. da Silva ${ }^{3, *}$ \\ ${ }^{1}$ Universidade Federal da Paraíba, Cidade Universitaria, PB, 58051-900, Brasil \\ ${ }^{2}$ Secretaria Municipal de Educação, Iguatu, Ceará, Brasil \\ ${ }^{3}$ Faculdade de Educação, Universidade Federal do Ceará, 60020-110, Fortaleza-Ceará, Brasil
}

*wandersondiogo@hotmail.com

(Recebido em 29 de abril de 2019; aceito em 29 de agosto de 2019)

\begin{abstract}
O processo de inclusão da pessoa com deficiência nas instituições de ensino tem sido um processo cada vez mais visível na sociedade brasileira, porém, em se tratando do ensino superior, essa realidade ainda pouco percebida quando analisada a partir das categorias acesso e permanência. Em se tratando da pessoa com deficiência visual, por exemplo, a inclusão é ainda mais dificultada em virtude da acessibilidade arquitetônica que, em geral, não existe. Assim, tendo como base o direito da pessoa com deficiência visual à sua livre circulação nos espaços de sociabilidade, este estudo buscou investigar a (in)acessibilidade arquitetônica presente em um campus universitário multi-institucional localizado no município de Iguatu/CE, que possui dois alunos cegos matriculados em um dos seus cursos. Assim, configurando-se como um estudo descritivo, realizou-se uma visitação à referida instituição a fim de verificar aspectos da sua arquitetura que estão ou não em conformidade com a NBR 9050/ABNT que versa sobre a acessibilidade para pessoas com deficiência visual (cegos e baixa visão). A partir de registros fotográficos e de anotações em um diário de campo, verificou-se que, embora a instituição tenha sido inaugurada recentemente, não há nenhuma acessibilidade arquitetônica em seus espaços, revelando sua dissonância com a referida legislação, culminando em um conjunto de barreiras arquitetônicas que dificultam e/ou impedem a permanência e livre circulação de pessoas com deficiência visual em seus espaços.

Palavras-chave: acessibilidade arquitetônica, deficiência visual, ensino superior.
\end{abstract}

The process of inclusion of people with disabilities in educational institutions has been an increasingly visible process in Brazilian society. However, in the case of higher education, this reality is little happens when analyzed from the categories of access and permanence. When it comes to the visually impaired person, for example, inclusion is made even more difficult by virtue of architectural accessibility that generally does not exist. Such, based on the right of the person with visual impairment to their free movement in spaces of sociability, this study sought to investigate the architectural (in) accessibility present in a multi-institutional university campus located in the municipality of Iguatu/CE, which has two blind students enrolled in one of their courses. Thus, as a descriptive study, a visit was made to this institution in order to verify aspects of its architecture that are or are not in compliance with the NBR 9050/ABNT that deals with the accessibility for people with visual impairment (blind and low vision). From photographic records and annotations in a field diary, it was found that, although the institution was recently inaugurated, there is no architectural accessibility in its spaces, revealing its dissonance with said legislation, culminating in a set of barriers that impede and/or impede the permanence and free movement of visually impaired people in their spaces.

Keywords: architectural accessibility, visual impairment, higher education.

\section{INTRODUÇÃO}

A inclusão de pessoas com deficiência nas instituições brasileiras de ensino, seja na educação básica ou no ensino superior, sempre representou uma grande problemática tendo em vista o longo processo de exclusão desses sujeitos em todos os espaços da sociedade. $\mathrm{O}$ direito à educação 
formal lhes foi negado durante séculos, sendo este garantido legalmente, de fato, apenas recentemente na virada do século XX para o século XXI, sobretudo a partir da lei n. 9.394, de 20 de dezembro de 1996, que instituiu as diretrizes e bases da educação nacional (LDB).

Embora a Educação Especial se configure como uma modalidade transversal do sistema educacional brasileiro [1] subsidiada por uma ampla legislação federal, na prática, a permanência do seu público-alvo nas instituições comuns de ensino ainda é baixa, fazendo com que nas instituições de ensino superior (IES) menos de $0,5 \%$ dos seus alunos sejam pessoas com deficiência, transtornos globais do desenvolvimento, superdotação ou altas habilidades [2].

Inquestionavelmente, a LDB representa um significativo e importante avanço para a inclusão escolar desse grupo populacional, mas o ingresso por si só não garante com que sua inclusão na escola comum aconteça, pois há necessidade de políticas públicas que subsidiem, também, a permanência desses alunos nestes espaços visando uma educação com e de qualidade para todos [3].

Nesse contexto, as pessoas que possuem deficiência visual (cegueira e baixa visão) tendem a enfrentar um conjunto ainda maior de obstáculos no seu cotidiano em decorrência da ausência de acessibilidade, sobretudo arquitetônica nos diversos espaços da sociedade, sejam estes públicos ou privados, dificultando o seu livre processo de orientação e mobilidade [4]. Nesse sentido, o presente estudo buscou investigar a (in)acessibilidade arquitetônica para a pessoa com deficiência visual nos espaços de um campus universitário multi-institucional que sedia duas IES públicas estaduais no mesmo espaço localizado no município de Iguatu-CE, bem como verificar se a disposição dos equipamentos arquitetônicos do campus está ou não em consonância com o que estabelece a norma brasileira 9050 da Associação Brasileira de Normas Técnicas (ABNT), justificando-se em decorrência das reivindicações sobre acessibilidade arquitetônica do referido campus externalizadas pelos alunos cegos que estudam e frequentam este espaço, bem como pela necessidade de se direcionar estudos à essa temática ainda pouco explorada pela literatura.

\section{A ACESSIBILIDADE ARQUITETÔNICA COMO SUBSÍDIO PARA A INCLUSÃO DE PESSOA COM DEFICIENCIA VISUAL NO ENSINO SUPERIOR}

Durante séculos as instituições de ensino superior no Brasil assumiram uma postura excludente e elitista, atuando para consolidar as condições capitalistas que se configuravam e se configuram até hoje no país, tendo como objetivos claros na defesa de "[...] que a universidade deveria estar voltada para a formação da elite e para a seleção dos mais capazes" [5]. A partir da sua abertura para população brasileira com indícios de democratização e expansão, as IES foram se modificando em decorrência das demandas sócioeducacionais que foram emergindo, dentre as quais está a inclusão das pessoas público-alvo da Educação Especial forjando, assim, iniciativas para a construção de um sistema educacional inclusivo.

A Declaração Mundial de Educação para Todos, resultado da Conferência Mundial da Organização das Nações Unidas para a Educação, a Ciência e a Cultura (UNESCO), em 1990, representa, nesse cenário, um marco constituinte para a educação inclusiva ao tratar da universalização da educação formal com base na promoção da equidade e da superação das desigualdades educacionais por parte dos Estados [6]. O direito à educação para todas as pessoas foi reafirmada, posteriormente, na Declaração de Salamanca, em 1994, ao denunciar o sistema educacional excludente até então consolidado em diversos países, dentre os quais está o Brasil [7].

Ainda na década de 1990, surge a LDB reconhecendo a Educação Especial como modalidade transversal do sistema educacional brasileiro, subsidiando o acesso das pessoas com deficiência ${ }^{1}$ à escola comum, todavia, há que se discutir a categoria permanência, uma vez que existem diversas barreiras que dificultam a concretização da Educação Especial na perspectiva da educação inclusiva nas instituições de ensino, sobretudo nas IES, cuja acessibilidade arquitetônica, por exemplo, é falha ou inexistente na maioria dos casos [8].

\footnotetext{
${ }^{1}$ A partir da lei no 12.796, de 4 de abril de 2013, a Educação Especial passou a contar com um públicoalvo maior, contemplando pessoas com e sem deficiência, como é o caso das pessoas que possuem transtornos globais do desenvolvimento, superdotação ou altas habilidades [10].
} 
No que diz respeito à pessoa cega, na maioria dos casos, esta apresenta mobilidade reduzida em decorrência da ausência da visão que é potencializada pela inexistência de ambientes e espaços acessíveis que lhes permita uma locomoção de forma segura e com o máximo de autonomia possível. Assim, a orientação e mobilidade deve ser trabalhada com as pessoas que apresentam a deficiência visual, sobretudo cegueira, visando lhes fornecer uma maior autonomia e independência para a realização de tarefas no seu cotidiano.

Nesse processo de orientação e mobilidade, assumem um importante papel as Tecnologias Assistivas (TA) como "um auxílio que promoverá a ampliação de uma habilidade funcional deficitária ou possibilitará a realização da função desejada e que se encontra impedida por circunstância de deficiência ou pelo envelhecimento" [9]. Esses recursos e serviços prestados pelas TAs como a bengala, o cão guia, ou sinais audíveis, por exemplo, promovem condições de uma vida mais independente à pessoa com esse tipo de deficiência em diversos espaços.

No entanto, mesmo com essas possibilidades, a pessoa com deficiência visual enfrenta diversos desafios dentro das IES que não possuem acessibilidade arquitetônica, embora a legislação estabeleça tal obrigatoriedade. Dessa forma, apropriando-se do discurso da ausência de acessibilidade arquitetônica e pedagógica, as instituições de ensino buscam 'justificar' a (re)produção da exclusão educacional das pessoas com deficiência, especialmente visual, mas não buscam saídas para reverter esse cenário discriminatório. E é assim que "o direito à educação esbarra no problema da igualdade de oportunidades, que não se compatibiliza com os ideais inclusivos, pois muitas vezes essa igualdade está a serviço da exclusão e até a justifica" [11].

\section{O AMPARO LEGAL DA ACESSIBILDADE ARQUITETÔNICA NO BRASIL: ALGUNS OLHARES}

A acessibilidade arquitetônica é um dos recursos que subsidia a permanência da pessoa com deficiência nos diversos espaços da sociedade. Nesse cenário, por se tratar de uma tarefa fundamental para que a pessoa com deficiência visual obtenha autonomia e segurança na universidade, faz-se necessário a união de forças entre Estado, sociedade e família para a garantia da acessibilidade nos espaços públicos, assim definida como a:

[...] possibilidade e condição de alcance para utilização, com segurança e autonomia, de espaços, mobiliários, equipamentos urbanos, edificações, transportes, informação e comunicação, inclusive seus sistemas e tecnologias, bem como de outros serviços e instalações abertos ao público, de uso público ou privados de uso coletivo, tanto na zona urbana como na rural, por pessoa com deficiência ou com mobilidade reduzida [12].

A acessibilidade é garantida pela Constituição Federal de 1988 ao estabelecer que a mesma "[...] disporá sobre normas de construção dos logradouros e dos edifícios de uso público e de fabricação de veículos de transporte coletivo, a fim de garantir acesso adequado às pessoas portadoras de deficiência ${ }^{2 "}$ [13]. Ainda, a Constituição passou a assegurar, em seu Art. 244, "[...] a adaptação dos logradouros, dos edifícios de uso público e dos veículos de transporte coletivo atualmente existentes a fim de garantir acesso adequado às pessoas portadoras de deficiência [...]" [13].

Uma das finalidades da acessibilidade arquitetônica é proporcionar condições de acesso e permanência nos espaços de sociabilidade que, por sua vez, resultam numa melhoria de vida para a pessoa com deficiência visual, ofertando recursos e condições mais inclusivas para o desenvolvimento de sua autonomia, por exemplo. Dessa forma, negar a possibilidade dessa acessibilidade é violar diretamente o que preconiza a Constituição Federal ao estabelecer que todas as pessoas " [...] são iguais perante a lei, sem distinção de qualquer natureza, garantindo-se aos brasileiros e aos estrangeiros residentes no País a inviolabilidade do direito à vida, à liberdade, à igualdade, à segurança e à propriedade [...]" [13].

Assim, as barreiras arquitetônicas retiram o direito da pessoa com deficiência visual da livre circulação, impossibilitando a promoção da igualdade e da inclusão, sendo estas "[...] qualquer

${ }^{2} \mathrm{O}$ termo "portador de deficiência" está em desuso, sendo substituído por "pessoa com deficiência". 
entrave, obstáculo, atitude ou comportamento que limite ou impeça a participação social da pessoa, bem como o gozo, a fruição e o exercício de seus direitos à acessibilidade [...]" [12].

Além dos documentos já citados, o decreto de $n^{\circ}$. 5.296, de 2 de dezembro de 2004, que regulamenta as leis $\mathrm{n}^{\circ} 10.048$, de 8 de novembro de 2000, e 10.098, de 19 de dezembro de 2000, descreve, em seu capítulo IV, orientações sobre a implementação dos edifícios com acessibilidade, estabelecendo que "a concepção e a implantação dos projetos arquitetônicos e urbanísticos devem atender aos princípios do desenho universal, tendo como referências básicas as normas técnicas de acessibilidade da ABNT [...]" [14].

Assim, a Associação Brasileira de Normas Técnicas (ABNT) representa uma referência legal a ser observado pelos profissionais responsáveis pela criação de projetos arquitetônicos a fim de que os mesmos estejam em consonância com o conceito do desenho universal que:

\begin{abstract}
[...] propõe uma arquitetura e um design mais centrados no ser humano e na sua diversidade. Estabelece critérios para que edificações, ambientes internos, urbanos e produtos atendam a um maior número de usuários, independentemente de suas características físicas, habilidades e faixa etária, favorecendo a biodiversidade humana e proporcionando uma melhor ergonomia para todos [12].
\end{abstract}

A norma brasileira (NBR) 9050/2015 da ABNT estabelece normas de acessibilidade para edificações, mobiliário, espaços e equipamentos urbanos para que as pessoas possam utilizar " [...] de maneira autônoma, independente e segura do ambiente, edificações, mobiliário, equipamentos urbanos e elementos à maior quantidade possível de pessoas, independentemente de idade, estatura ou limitação de mobilidade ou percepção" [15]. Traz, também, o conceito de acessibilidade como sendo "a possibilidade e condição de alcance, percepção e entendimento para a utilização com segurança e autonomia de edificações, espaço, mobiliário, equipamento urbano e elementos" [15].

Nesse contexto, as IES enquanto espaços de sociabilidade devem analisar as barreiras arquitetônica existentes em suas instalações objetivando oferecer pleno acesso e permanência à pessoa com deficiência visual aos seus espaços, proporcionando progressiva e constante "[...] condições de acesso e utilização de todos os seus ambientes ou compartimentos para pessoas portadoras de deficiência ou com mobilidade reduzida, inclusive salas de aula, bibliotecas, auditórios, ginásios e instalações desportivas, laboratórios, áreas de lazer e sanitários" [14].

\title{
4. MATERIAL E MÉTODOS
}

Esta pesquisa foi desenvolvida com base na abordagem qualitativa que buscou compreender e interpretar um determinado acontecimento a fim de encontrar respostas ou hipóteses para descrever tal realidade [16]. Para tal, adotou-se o estudo descritivo que "[...] têm como objetivo primordial a descrição das características de determinada população ou fenômeno ou o estabelecimento de relações entre variáveis" [17].

O estudo foi desenvolvido em um campus universitário multi-institucional localizado no município de Iguatu/CE, inaugurado em 2015 para acolher campi de duas IES públicas estaduais do estado funcionando no mesmo espaço. A escolha dessa instituição se deu em decorrência do seu edifício moderno e recentemente inaugurado, bem como pela existência de alunos com deficiência visual (cegueira) regularmente matriculados nos cursos de graduação do campus.

Os dados foram coletados a partir de uma visita ao campus, gerados a partir da observação que resultou em registros fotográficos e anotações no caderno de campo para serem confrontados com os dispostos das normas de acessibilidade da ABNT - NBR 9050.

\section{RESULTADOS E DISCUSSÃO}

Ainda que de forma tardia e lenta, o acesso das pessoas com deficiência visual ao ensino superior no Brasil está avançando, revelando a urgência de que os "aspectos educacionais relacionados ao processo de atendimento acadêmico deste grupo sejam trazidos ao debate, 
buscando oferecer condições mínimas de acesso e permanência dessa população no meio universitário" [18]. Assim, discussões acerca dessa problemática emergiram na instituição pesquisada a partir do ingresso de uma aluna e um aluno cegos no curso de licenciatura em Letras da em uma das IES situadas no campus pesquisado nos anos de 2016 e 2017, respectivamente, os quais, constantemente queixam-se da ausência da acessibilidade arquitetônica neste espaço.

Conforme estabelecido pela ABNT [15], "todas as entradas, bem como as rotas de interligação às funções do edifício, devem ser acessíveis" para que as pessoas com deficiência possam ter autonomia e segurança durante todo o seu trajeto nas instituições de ensino, por exemplo. $\mathrm{Na}$ instituição pesquisada, a entrada principal possui a calçada rebaixada, no entanto, a entrada para pedestres é estreita e encontra-se ao lado da entrada de automóveis podendo ocasionar acidentes para as pessoas cegas devido a inexistência de sinalização audiovisual. O estacionamento, por sua vez, encontra-se logo à frente da entrada, cuja faixa de pedestres apresenta-se em uma rota não acessível conforme verifica-se na Figura 1.

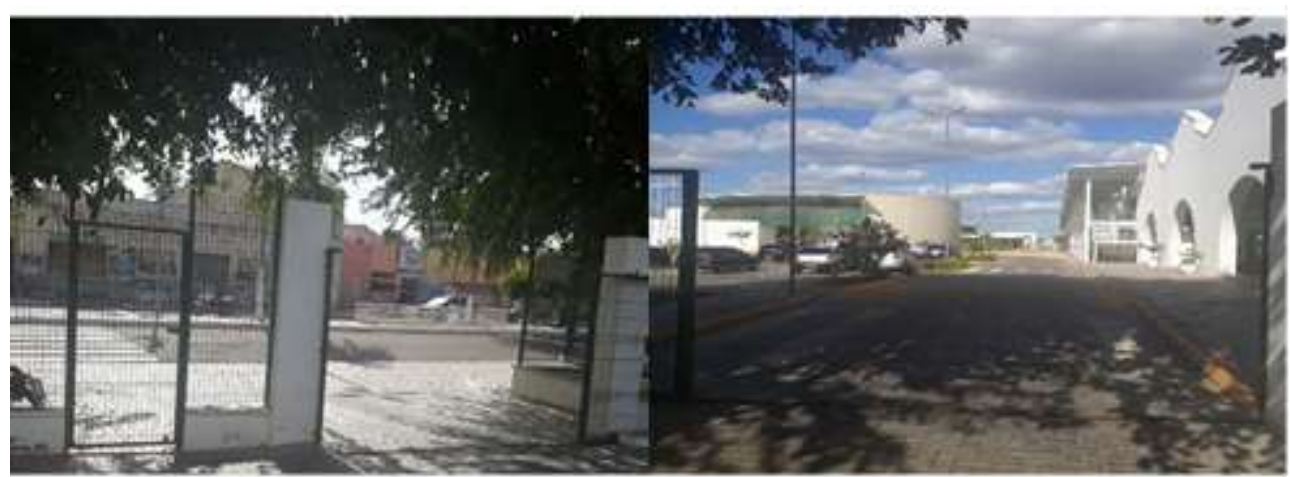

Figura 1: Entrada do campus. Fonte: Os autores

No trajeto entre os blocos que dão acesso às salas de aula, laboratórios, auditório, biblioteca, refeitório e demais áreas de circulação do campus, não existem rotas acessíveis que proporcionem um "trajeto contínuo, desobstruído e sinalizado, que conecte os ambientes externos ou internos de espaços e edificações que possam ser utilizados, de forma autônoma e segura, por todas as pessoas, inclusive aquelas com deficiência e mobilidade reduzida" [15].

$\mathrm{O}$ acesso às salas de aula possui um quantitativo considerável de obstáculos que dificultam a livre circulação dos alunos cegos na instituição, uma vez que nos locais que deveriam possuir rotas de interligação como um corredor, por exemplo, existem escadas suspensas junto à estrutura de ferro com colunas verticais e horizontais, dificultando a locomoção dos alunos em questão, podendo resultar, inclusive, em acidentes graves para estes alunos, conforme verifica-se na Figura 2.

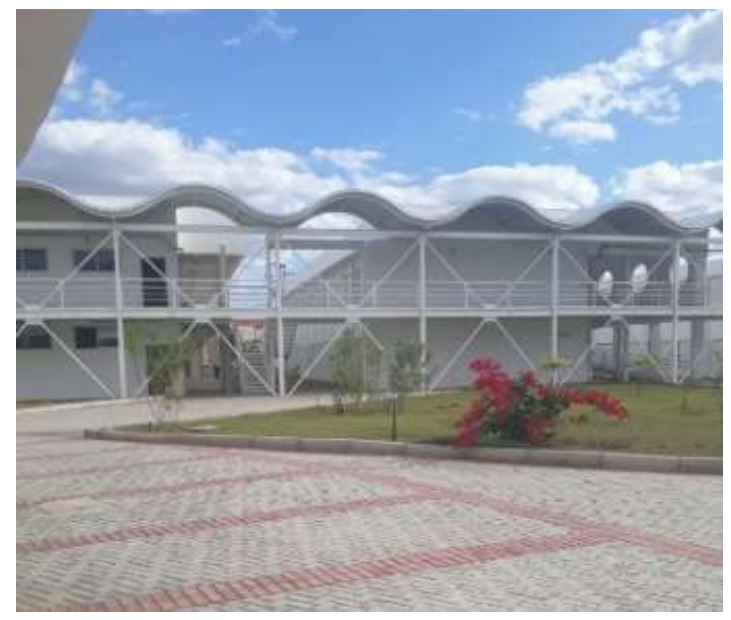

Figura 2: Blocos das salas de aula do campus. Fonte: Os autores 
Nesses obstáculos não identificáveis pela bengala não há sinalização de alerta, seja esta sonora ou tátil que visa "informar à pessoa com deficiência visual sobre a existência de desníveis ou situações de risco permanente, como objetos suspensos não detectáveis pela bengala longa" [15]. $\mathrm{O}$ piso superior é desprovido da mesma forma dos recursos apontados para o andar inferior. Nas escadas não existe orientação por meio de sinalização alerta que é fundamental para a pessoa cega identificar e utilizar equipamentos e serviços, bem como situar-se nos percursos localizando o início e término de escadas e rampas (Figura 3).

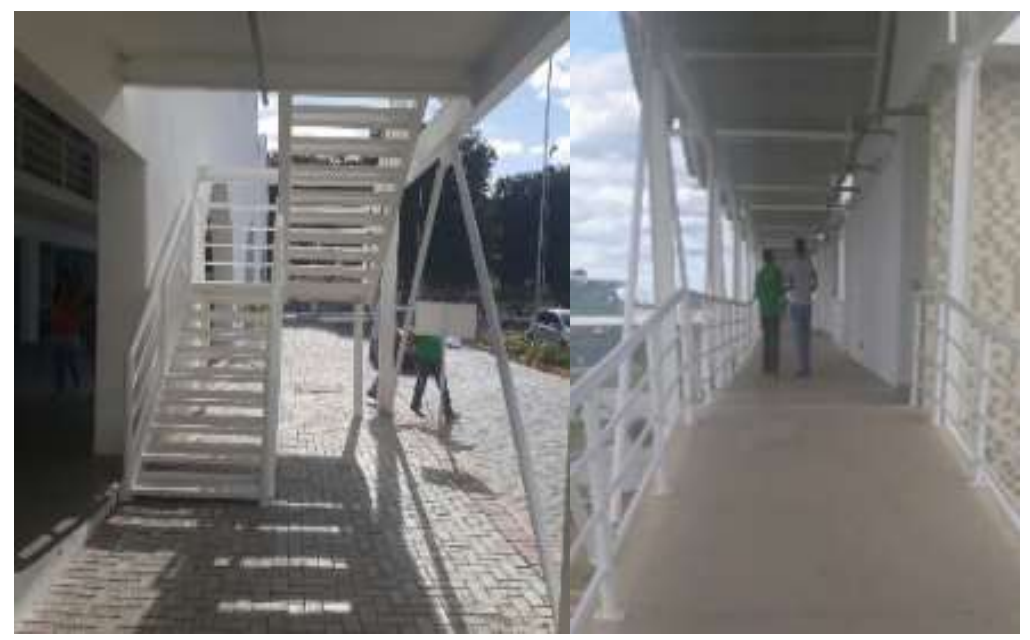

Figura 3: Escada e corredor que dá acesso às salas de aula dos blocos superiores do campus. Fonte: Os autores.

No campus não existe piso tátil "caracterizado por textura e cor contrastantes em relação ao piso adjacente, destinado a constituir alerta ou linha-guia, servindo de orientação, principalmente, às pessoas com deficiência visual ou baixa visão" [15]. Do mesmo modo, é ausente a sinalização tátil direcional e de alerta, dificultando a orientação espacial da pessoa cega, fazendo com que ela possa "[...] se deparar com situações de perigo ou obstáculos" [15].

Outra ausência observada é a do plano e mapas acessíveis que são "[...] representações visuais, táteis e/ou sonoras que servem para orientação e localização de lugares, rotas, fenômenos geográficos, cartográficos e espaciais [15]. Esse mapa permite à pessoa com deficiência visual acessar e localizar-se dentro dos edifícios, por exemplo, de forma segura e com o máximo de autonomia possível.

O auditório da instituição apresenta-se em total discordância com a NBR 9050, sendo explícitos os diversos obstáculos que dificultam a locomoção da pessoa cega. Neste, há ausência de piso tátil, sinalização sonora e tátil, espaços reservados para pessoa com deficiência ou com mobilidade reduzida, rampas para acesso ao palco e corrimão na escada, conforme exposto na Figura 4, revelando um descumprimento da legislação e, também, a (re)produção e manutenção da exclusão institucionalizada.

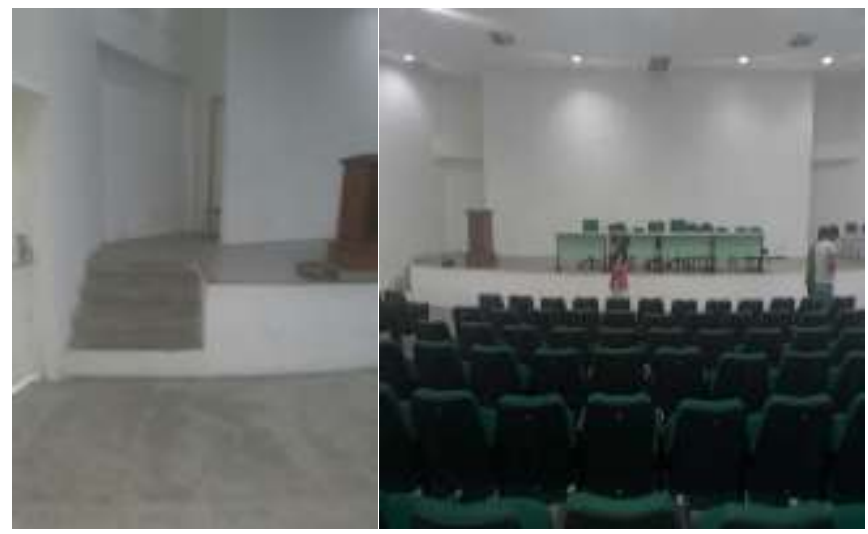

Figura 4: Auditório central do campus. Fonte: Os autores 
No centro de convivência, além dos problemas já citados, há obstáculos arquitetônicos no piso: um círculo com desnível profundo sem sinalização de alerta dificulta o percurso dos alunos, conforme apontado na Figura 5. Neste espaço deveria existir uma rota acessível, pois "[...] em complexos educacionais e campi universitários, quando existirem equipamentos complementares, como piscinas, livrarias, centros acadêmicos, locais de culto, locais de exposições, praças, locais de hospedagem, ambulatórios, bancos e outros, estes devem ser acessíveis" [15].

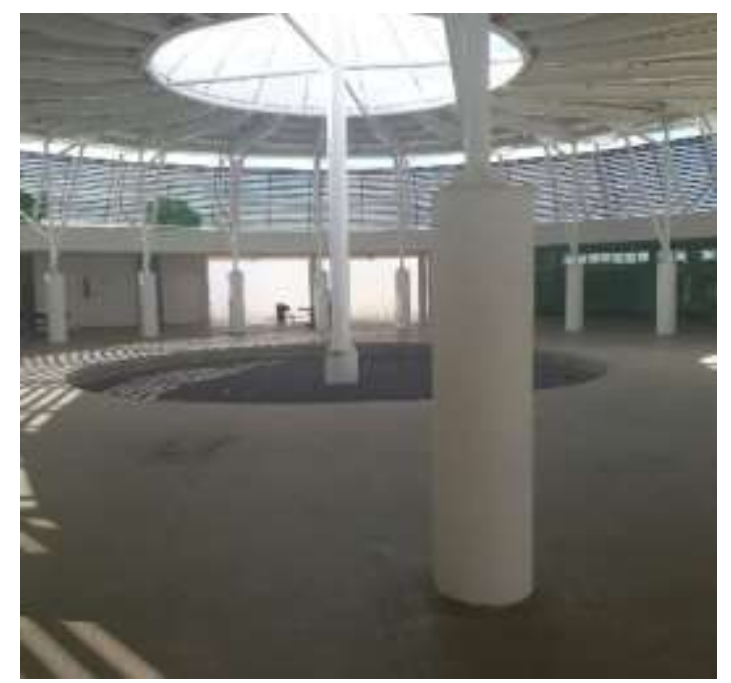

Figura 5: Centro de convivências do campus. Fonte: Os autores

Por sua vez, a biblioteca que deve atender às seções 9 e 10 da NBR 9050/2015, encontra-se sem rota acessível, além de não existir nenhuma garantia de serviço de apoio às pessoas cegas, tais como Tecnologias Assistivas que recaem, dentre outras finalidades, em " [...] garantir recursos audiovisuais, publicações em texto digital acessível e serviço de apoio [...]. Recomenda-se que possuam também publicações em Braille" [15]. Na biblioteca da instituição pesquisada existe um elevador para cadeirantes que dá acesso à sala de estudos no piso superior, porém, o mesmo encontrava-se com problemas de funcionamento durante a coleta dos dados pela falta de manutenção.

As lixeiras estão localizadas dentro das faixas de livre circulação contrariando os dispositivos legais da norma brasileira de acessibilidade ao estabelecerem que "quando instalados em áreas públicas, devem ser localizados fora das faixas livres de circulação" [15]. Do mesmo modo, os extintores de incêndio, quadros de distribuição de energia e os bebedouros de água apresentaramse sem nenhum tipo de sinalização visual ou audível. A inacessibilidade também é perceptível nos banheiros da instituição, seja para a pessoa com deficiência visual ou física.

$\mathrm{O}$ acesso à única rampa do campus, bem como à quadra, piscina, refeitório, auditório, biblioteca e administração é inviável para a pessoa cega, pois são ambientes isolados que não possuem rotas acessíveis nem pontos de referência para que a pessoa cega possa, sozinha, chegar a eles. Existem, também, vários obstáculos arquitetônicos que dificultam a orientação e mobilidade da pessoa com deficiência visual. Na mesma situação estão as salas de apoio a projetos e os laboratórios da instituição, pois nesses ambientes não existem mapa para localização nem dispõe de material em alto relevo, braille ou software de sistemas de voz.

No laboratório de Biologia, no entanto, foi possível encontrar alguns materiais didáticopedagógicos em alto-relevo e táteis para alunos com deficiência visual (cegos e baixa visão) a ser utilizado no ensino de Biologia/Ciências produzidos pelos alunos do curso de licenciatura em Ciências Biológicas de uma das IES do campus. Todavia, a falta de sinalização e piso tátil acarretam objeções para a efetivação da orientação e mobilidade autônoma da pessoa cega e dificulta a acessibilidade dentro da instituição.

Nesse contexto, diversas são as barreiras encontradas para e pela pessoa com deficiência visual ao ingressar no ensino superior no referido campus, sendo estas não apenas de cunho arquitetônico, mas atitudinal tendo em vista a recém inauguração do mesmo que, mesmo após décadas de obrigatoriedade de se ter espaços de sociabilidade arquitetonicamente inclusivos e 
acessíveis, ainda são poucas as instituições que, de fato, são acessíveis para pessoas com deficiência visual.

\section{CONCLUSÃO}

Neste estudo verificou-se que na instituição pesquisada inexiste acessibilidade arquitetônica para a pessoa com deficiência visual, causando impedimentos à orientação e mobilidade, sobretudo à pessoa cega, sendo um empecilho para a materialização da sua inclusão e autonomia no ensino superior. Embora o campus tenha sido construído recentemente, em 2015, percebe-se que este se encontra em total desacordo com as normas de acessibilidade da ABNT e demais legislações acerca da acessibilidade arquitetônica. Pode até parecer contraditória essa realidade quando se considera que o edifício foi construído recentemente, no entanto, tal fato nos remete à reflexão sobre a dificuldade em aceitar a diversidade, resultando na manutenção de um direito ao ensino superior elitista, normativo e excludente.

Assim, o que se percebe é que mesmo com a legislação e o debate sobre a inclusão da pessoa com deficiência tão presente na universidade e fora dela, ainda são encontradas com facilidade diversas barreiras atitudinais e arquitetônicas que em nada contribuem para o processo de inclusão das pessoas com deficiência. Nesse sentido, esse estudo dá visibilidade aos impedimentos arquitetônicos que circundam o edifício do campus analisado. Por isso, o trabalho difunde conhecimento sobre o tema para possíveis abordagens que contribuam no processo inclusivo das pessoas com deficiência para que esse público tenha condições de acesso e permanência nas instituições de ensino.

Desse modo, o resultado da pesquisa evidencia a importância da acessibilidade e de que a legislação é totalmente descumprida e, com isso, não se efetivam as políticas públicas de inclusão, educação e acessibilidade social. Portanto, fica o desafio de refletir e expor as instancias públicas e a sociedade em geral o descaso com a acessibilidade arquitetônica que necessitam ser corrigidas, pois tais barreiras inviabilizam a construção de uma universidade inclusiva e para todos.

\section{REFERÊNCIAS BIBLIOGRÁFICAS}

1. Brasil. Lei no 9.394, de 20 de dezembro de 1996. Estabelece as diretrizes e bases da educação nacional.

2. Martins SESO, Leite LP, Ciantelli APC. Mapeamento a análise da matrícula de estudantes com deficiência em três Universidades públicas brasileiras. Psicol Esc Educ. 2018;22(n. esp.):15-23, doi:10.1590/2175-35392018033.

3. Silva WDA, Rodrigues IC, Araujo JMP, Silva MM. Silva. Os impasses da materialização da aprendizagem de alunos com deficiência visual no ensino de Química. Jornada Ibero-Americana de Pesquisas em Políticas Educacionais e Experiências Interdisciplinares na Educação. Natal: IFRN; 2017. p. 280-291.

4. Silva WDA, Dantas LM. Deficiência visual e inclusão escolar: um estudo acerca da acessibilidade arquitetônica e pedagógica nos laboratórios de Ciências do Liceu de Iguatu - CE. In: Freitas LPT, Façanha AR, editors. Orientação e Mobilidade: Ensaios. Fortaleza: IFCE; 2018

5. Orso PJ. A criação da Universidade e o projeto burguês de educação no Brasil. In: Orso PJ, editors. Educação, sociedade de classes e reformas universitárias. Campinas: Autores Associados; 2007.

6. Unesco. Declaração Mundial sobre educação para todos: satisfação das necessidades básicas de aprendizagem. Jomtien, Tailândia: Unesco; 1990.

7. Unesco. Declaração de Salamanca: sobre princípios, política e práticas na área das necessidades educativas especiais. Salamanca, Espanha: Unesco; 1994.

8. Garcia RAB, Bacarin APS, Leonardo NST. Acessibilidade e permanência na educação superior: percepção de estudantes com deficiência. Psicol Esc Educ. 2018;(esp):33-40. doi:10.1590/21753539/2018/035

9. Bersch R. Introdução à Tecnologia Assistiva. Porto Alegre: Assistiva; 2017.

10. Brasil. Lei $n^{\circ} 12.796$, de 4 de abril de 2013. Altera a Lei no 9.394, de 20 de dezembro de 1996, que estabelece as diretrizes e bases da educação nacional, para dispor sobre a formação dos profissionais da educação e dar outras providências.

11. Mantoan MTÉ. Inclusão escolar: caminhos, descaminhos, desafios, perspectivas. In: Mantoan MTÉ, editors. O desafio das diferenças nas escolas. Petrópolis: Vozes; 2011.

12. Brasil. Lei $\mathrm{n}^{\circ} 13.146$, de 6 de julho de 2015. Institui a Lei Brasileira de Inclusão da Pessoa com Deficiência (Estatuto da Pessoa com Deficiência). 
13. Brasil. Constituição da República Federativa do Brasil de 1988.

14. Brasil. Decreto $n^{\circ} 5.296$, de 2 de dezembro de 2004. Regulamenta as Leis nos 10.048, de 8 de novembro de 2000, que dá prioridade de atendimento às pessoas que especifica, e 10.098, de 19 de dezembro de 2000, que estabelece normas gerais e critérios básicos para a promoção da acessibilidade das pessoas portadoras de deficiência ou com mobilidade reduzida, e dá outras providências.

15. ABNT. Norma Técnica Brasileira 9050. Acessibilidade a edificação, mobiliário, espaços e equipamentos urbanos. São Paulo; 2015.

16. Oliveira MF. Metodologia científica: um manual para a realização de pesquisas em Administração. Catalão: UFG; 2011.

17. Gil AC. Métodos e técnicas de pesquisa social. São Paulo: Atlas; 2008.

18. Dechichi C, Silva LC, Gomide AB. Projeto Incluir: acesso e permanência na UFU. In: Dechichi C, Silva LC, editors. Inclusão Escolar e Educação Especial: teoria e prática na diversidade. Uberlândia: EDUFU; 2008. 